\title{
Defining Algorithmic Ideology: Using Ideology Critique to Scrutinize Corporate Search Engines
}

\author{
Astrid Mager \\ Institute of Technology Assessment, Austrian Academy of Sciences, Vienna, Aus- \\ tria, astrid.mager@oeaw.ac.at, http://www.astridmager.net
}

\begin{abstract}
This article conceptualizes "algorithmic ideology" as a valuable tool to understand and critique corporate search engines in the context of wider socio-political developments. Drawing on critical theory it shows how capitalist value-systems manifest in search technology, how they spread through algorithmic logics and how they are stabilized in society. Following philosophers like Althusser, Marx and Gramsci it elaborates how content providers and users contribute to Google's capital accumulation cycle and exploitation schemes that come along with it. In line with contemporary mass media and neoliberal politics they appear to be fostering capitalism and its "commodity fetishism" (Marx). It further reveals that the capitalist hegemony has to be constantly negotiated and renewed. This dynamic notion of ideology opens up the view for moments of struggle and counter-actions. "Organic intellectuals" (Gramsci) can play a central role in challenging powerful actors like Google and their algorithmic ideology. To pave the way towards more democratic information technology, however, requires more than single organic intellectuals. Additional obstacles need to be conquered, as I finally discuss.
\end{abstract}

Keywords: Search Engine, Algorithm, Critical Theory, Ideology, Capitalism, Social Practices, Net Politics, Social Movements

Acknowledgement: This research was funded by the Jubiläumsfonds of the Oesterreichische Nationalbank (OeNB), project number 14702. I would like to thank René König, Doris Allhutter and the reviewers of this journal for their helpful comments on the article.

\section{Introduction}

Corporate Internet technologies like Google, Facebook and co. have been described as mirroring the "Californian ideology". Google, in particular, has been interpreted as a paradigmatic example of a company deeply rooted in the economic culture of Silicon Valley with a strong belief in the democratic potential of information technology and the free market. "This new faith has emerged from a bizarre fusion of the cultural bohemianism of San Francisco with the hi-tech industries of Silicon Valley. Promoted in magazines, books, TV programmes, websites, newsgroups and Net conferences, the Californian Ideology promiscuously combines the free-wheeling spirit of the hippies and the entrepreneurial zeal of the yuppies" (Barbrook and Cameron 1996, 44). The Californian ideology encompasses ideals of both the political left and right. It reflects the disciplines of market economics and the freedoms of hippie artisanship. According to Barbrook and Cameron (1996) the Californian ideology is held by IT entrepreneurs and clearly linked to techno-determinism and American neoliberalism. It has become a buzzword for the business culture Google and other IT companies perform. It, however, fails to provide a thorough concept of ideology enabling us to analyze and criticize search engines in the context of wider socio-political developments and capitalist modes of production. Drawing on Marxian thinking critical Internet scholars (Pasquinelli 2009, Fuchs 2011a, 2011b) have scrutinized the political economy of search engines and new modes of exploitation that have been introduced along with search engines, social media, and other online services. In my own work, I have argued that search engines should not be seen as external to society, but rather as negotiated and shaped in society. They show us the face of capitalism because they were born and raised in a capitalist society. They embody an "algorithmic ideology" (Mager 2012a).

In this paper I aim to thoroughly define the notion "algorithmic ideology" by drawing on concepts from the tradition of critical theory, ideology critique first and foremost. I begin with discussing fundamental critique new media scholars have formulated regarding 
search engines and their biases, business models, and political economy. Drawing on thinkers like Althusser, Marx and Gramsci I further elaborate how individual users relate to "transnational informational capitalism" (Fuchs 2011a) as a whole, how they contribute to Google's capital accumulation cycle, and how the capitalist ideology endures and spreads through search engines. I further argue that the capitalist hegemony needs to be constantly renewed, which means that Google has to motivate users to comply with its practices, and that users may opt out of Google's capital accumulation cycle any time. What role "organic intellectuals" (Gramsci 2012) can play in challenging actors like Google and their algorithmic ideology in an age of "post-democracy" (Crouch 2004) will be finally discussed.

\section{Search Engine Critique}

Compared to utopian digital futures inherent in the Californian ideology, critical Internet and new media scholars have pictured more dystopian visions of online spaces increasingly occupied, organized and exploited by corporate players like Google. At the turn of the century Introna and Nissenbaum (2000) started questioning the mathematical purity of search algorithms like the PageRank. While Brin and Page (1998, see also Mayer 2009), the inventors of the PageRank, argued their algorithm would mathematically measure a website's value by using the number and quality of links a website gets from other websites, similarly to references in the academic context, Introna and Nissenbaum (2000) pointed to the political dimension of search engines. Systematically preferring big, wellconnected websites at the expense of smaller ones, search engines would construct a content bias and run counter to the democratic potential of the web according to the authors. Their claim was empirically confirmed by a number of studies in the past years. In the medical context, for example, well-established medical institutions and commercial health portals clearly outpace smaller websites such as self-help groups and NGOs (Seale 2005, Nettleton et al. 2005, Mager 2012b). Consequently, orthodox medical viewpoints are much more dominantly presented on the top of search engines than experiential medical knowledge and alternative accounts. Besides such snowball effects, popular algorithms like the PageRank trigger search engine optimization (SEO) strategies further contributing to information biases and the commodification of search results (Mager 2012b, Eklöf and Mager 2013).

Moreover, business models based on user-targeted advertising have come under attack in the past years. Elmer (2004) coins the core business model of the information economy the "service-for-profile" model, where users get services for free in exchange for personal data. Search engines, but also social networking platforms and other online services, turn these vast amounts of data into "user profiles" mirroring users' desires and needs. These individual or group profiles help search engines to localize and personalize search results, but also - more importantly - to personalize sponsored links, presented on the right side or on top of the "organic" search results in the case of Google, for example. In 2000, Google presented an automated advertising system called AdWords that targeted advertisements based on users' search terms. Imitating a technology originally invented by the search engine GoTo Google allowed advertisers to bid on how much they would like to pay to appear on top of sponsored search results in relation to individually chosen search terms. Later it began to syndicate cost-per-click advertisements to partner websites through its AdSense program, which allowed advertisers to relate their advertisements to a website's content ${ }^{1}$. This clever business model makes use of the "traffic commodity" (Van Couvering 2008) and has created gigantic annual revenues. Rather than taking over classical business models based on audiences (such as portals that collapsed during the dot-com crash), Google followed a new business model based on the 'traffic commodity', the flow of visitors from one website to the other (Van Couvering 2008).

\footnotetext{
${ }^{1}$ More information on Google AdWords and AdSense can be found on Google's website: http://www.google.com/intl/en/ads/ (accessed February 6, 2014).
} 
Google hence succeeded in aligning its technology with a business model that perfectly fits the network structure of the web.

At the same time, criticism concerning privacy violations, online surveillance and the exploitation of user data and practices has emerged. Having analyzed the political economy of Google from a Marxian perspective, Matteo Pasquinelli (2009) argues that Google's PageRank algorithm exploits the collective intelligence of the web since Google uses links from other websites to measure a websites' value. These links may be seen as a concretion of intelligence that is used by Google to create surplus value. Website providers' creativity is turned into profit without being compensated by Google. Christian Fuchs further conceptualizes user data and practices as integral part of Google's capital accumulation cycle. The simple acts of using Google search, locating places with Google maps, communicating with Gmail, browsing manuscripts with Google books, watching YouTube videos, or sharing images with Picasa and Google+, to mention but a few of the vast repertoire of Google services, leave a myriad of data traces Google collects, archives and turns into user profiles. The author hence concludes that "these are all applications that can give great benefits to humans. But at the level of the relations of production, Google is a profit-oriented, advertising-financed moneymaking machine that turns users and their data into a commodity. And the result is large-scale surveillance and the immanent undermining of liberal democracy's intrinsic privacy value" (Fuchs 2011b).

In a Marxist tradition the user may hence be seen as both the consumer constantly exposed to personalized ads and the commodity that is sold to advertising clients. These analyses of the political economy of Google are valuable contributions to the understanding of the commercial dimension of search engines and new modes of exploitation that come along with it. They show that capitalist modes of production are both continued and transformed in contemporary information economies. Fuchs (2011a) speaks of "transnational informational capitalism" to capture both the continuity and discontinuity of capitalism in the information age: "Transnational informational capitalism is the result of the dialectic of continuity and discontinuity that shapes capitalist development. Surplus value, exchange value, capital, commodities and competition are basic aspects of capitalism; how such forms are exactly produced, objectified, accumulated, and circulated is contingent and historical. They manifest themselves differently in different capitalist modes of development. In the informational mode of development surplus value production and capital accumulation manifest themselves increasingly in symbolic, "immaterial", informational commodities and cognitive, communicative, and co-operative labour. The accumulation of capital, power, and definition capacities on a transnational scale is strongly mediated by new media" (Fuchs 2011a, 128).

Other notions capturing tight entanglements between global information technology and capitalist structures are "the new spirit of capitalism" (Boltanski and Chiapello 2007), "immaterial labor" (Hardt and Negri 2000, 2004), or "cognitive capitalism" (Vercellone 2007 ), to cite but a few of the growing number of terms focusing on the political economy of new media (see also Fuchs 2011c). However, all these contributions cannot explain why search engines have become powerful actors in the first place and how they - and their algorithmic ideology - are stabilized in contemporary society. To better understand these dynamics the focus of analysis needs to be broadened and the variety of actors involved in the solidification of search technology should be taken into account. Since Internet companies do not operate in a societal vacuum, but rather incorporate and mirror societal values we need to go beyond the political economy of search engines and include ideological frameworks, material practices and socio-political factors in the analysis, as I show in the following pages.

\section{Ideology in Practice}

Ideology is a complex matter. It oscillates between epistemological ideas about true or false consciousness rooted in Marxist theory and sociological thinking concerned with the way ideas function in social practices. The classical Marxist concept of ideology relates to 
questions of dominant social power and the way signs, meanings and values help to reproduce power structures and, ultimately, class society (capitalism in particular, Herzogenrath-Amelung 2013). Sociological interpretations, in contrast, describe ideology as action-oriented sets of belief that sustain social life resembling neutral world views more than radical concepts of critique (for an in-depth discussion of ideology theories see Eagleton 1991). To define algorithmic ideology I focus on ideology concepts that perceive ideology as co-produced by social values and material practices. Rather than thinking of ideology as either a set of disembodied ideas or as a matter of social practices, I show that algorithmic ideology is both at the same time. It enables us to formulate search engine critique entrenched in empirical contexts, to raise empirical ideology critique. "The task of empirical ideology critique is to critically analyse ideologies in and about the media" (Fuchs 2011a, 327). In the following, I tease out ideology concepts that serve this purpose.

The first concept is Louis Althusser's notion of ideology as a matter of lived relations. "Ideology for Althusser is a particular organization of signifying practices which goes to constitute human beings as social subjects, and which produces the lived relations by which such subjects are connected to the dominant relations of production in a society" (Eagleton 1991, 18). In Althusser's belief ideology represents the way individuals relate to society as a whole. It is a matter of lived relations, but it also involves a range of beliefs and assumptions. Accordingly, it provides a concept of ideology that helps us to close the gap between ideology as a value system imposed by the ruling class and ideology as a concept emerging from social practices. It offers a bridge between the ideological superstructure and the economic base to speak in the words of Karl Marx. In fact, Marx himself introduced the notion of "commodity fetishism" in his later work to pay reference to interrelations between values and material cultures. In his first volume of Capital (Marx 1867) he argues that in capitalist society social relations are governed by interactions of the commodities they produce. "By virtue of this 'commodity fetishism', real human relations appear, mystifyingly, as relations between things; and this has several consequences of an ideological kind" (Eagleton 1991, 85). One of these consequences, according to Eagleton $(1991,85)$, is that ideology is no longer a question of (true or false) consciousness, but that it is anchored in reality, "in the day-to-day economic operations of the capitalist system". Accordingly, ideology is not just a matter of thinking about a situation, but it is rather inscribed in the situation itself. "It is no good my reminding myself that I am opposed to racism as I sit on a park bench marked 'Whites Only'; by the act of sitting on it, I have supported and perpetuated racist ideology. The ideology, so to speak, is in the bench, not in my head" (Eagleton 1991, 40). Consequently, ideology can no longer be conceptualized as solely springing from a dominant class, but rather as being enacted, stabilized, and manifested in society.

Philosophers like Theodor Adorno or Herbert Marcuse interpret the capitalist ideology as a monolithic concept reaching from commodity fetishism and speech habits to political bureaucracy and technological thought. This perception of capitalist ideology takes capitalism at face value and makes critique futile since all corners of society are pervaded by capitalism (Eagleton 1991). Antonio Gramsci, in contrast, offers a more dynamic concept of ideology involving struggle. Gramsci's work on "hegemony" interprets dominant value systems not as static and generally accepted, but rather as constantly negotiated in society. It shows that effort and strategies are needed to spread hegemonic values in society and that hegemonized groups need to participate in this process. In his prison notebooks Gramsci (2012) enriches the notion of ideology by introducing a dynamic feature and explaining that hegemonic values have to be permanently renewed, recreated and defended. Hegemony implicates struggle and negotiation and thus "lends this otherwise somewhat abstract term a material body and political cutting edge" (Eagleton 1991, 115). "To win hegemony, in Gramsci's view, is to establish moral, political and intellectual leadership in social life by diffusing one's own 'world view' throughout the fabric of society as a whole, thus equating one's own interests with the interests of society at large" (Eagleton 1991, 116). A central moment, according to Gramsci $(2012,181)$, is "that in which one 
becomes aware that one's own corporate interests, in their present and future development, transcend the corporate limits of the purely economic class, and can and must become the interest of other subordinate groups too". Consent is reached by way of creating win-win situations that make individuals play by the rules of capitalism. In turn, hegemonized groups actively contribute to power relations and solidify hegemonic value systems. "Hegemony presupposes an active and practical involvement of the hegemonized group, quite unlike the static, totalizing and passive subordination implied by the dominant ideology concept" (Gramsci, in Forgacs 1988, 424). In the following, I show how these concepts help us to define "algorithmic ideology".

\section{Algorithmic ideology}

Althusser's notion of ideology as a matter of lived relations enables us to conceptualize how individual users relate to "transnational informational capitalism" (Fuchs 2011a) as a whole and how the capitalist ideology spreads through search algorithms. Google uses websites and links provided by content creators to index the web and rank its search results. It further employs user data to improve its algorithm and, more importantly, to adapt sponsored links to users' preferences and needs. In Marx's terms Google uses both content providers' and users' practices to create surplus value (Pasquinelli 2009, Fuchs 2011a, 2011b). Algorithmic logics, code, external content, link structures, user data, clicking behavior, user-targeted advertising, financial transactions all act together and take effect in a single Google search. Capitalist modes of production are enmeshed with technical features and individual practices. The ideological superstructure and the economic base meet with and feed each other in every singly Google query. Similarly to sustaining racist ideology by sitting on a park bench marked "Whites Only", conducting a Google search may hence be seen as sustaining capitalist ideology; whether consciously or not. The ideology is in the search engine and acts through algorithmic logics and computational systems. Search engines like Google may hence be seen as perpetuating the capitalist ideology through their supposedly neutral search algorithms (Mager 2012a). Undoubtedly, the role of content providers and users is central in this economic process. But how are providers and users steeped into Google's capital accumulation cycle and why do they play by the rules?

In critical internet research producers and users of web content are often described as exploited by corporate internet companies and turned into a "prosumer commodity" (Fuchs 2011b), as argued earlier. The whole debate about digital or cognitive labor conceptualizes users primarily as victims of Internet companies and their perfidious practices. "Prosumers", however, are not forced to use services by Google, Facebook and others, but rather do so of their own free will. The Internet is both a factory and a playground after all (Scholz 2013). Content providers and users are not simply exploited by Google (and others). Quite on the contrary, they clearly benefit from search services Google provides. Website providers aim to gain visibility in the multitude of web information and reach users to communicate their content. Users, in turn, want to conveniently find information and filter them along their needs. Search engines have managed to satisfy both content providers' and users' needs with their services. Especially, Google has become an "obligatory passage point" providers and users have to pass to reach their own goals (Mager 2009, Röhle 2009). Also, services like Google AdWords and Google AdSense would not work if people would not advertise with or click on Google ads. This dynamic perfectly exemplifies Gramsci's central moment in winning hegemony over hegemonized groups, the moment "in which one becomes aware that one's own corporate interests [...] become the interests of other subordinate groups" (Gramsci 2012, 181). It is the moment where "prosumers" start playing by the rules of transnational informational capitalism because Google (and other IT companies) serve their own purposes; a supposedly win-win situation is established. Prosumers are "steeped into" the ruling ideology to speak with Althusser: "All the agents of production, exploitation and repression, not to speak of the 'professionals of ideology' (Marx), must in one way or another be 'steeped' in this ideology in order to per- 
form their tasks 'conscientiously' - the tasks of the exploited (the proletarians), of the exploiters (the capitalists), of the exploiters' auxiliaries (the managers), or of the high priests of the ruling ideology (its 'functionaries'), etc" (Althusser 1971).

Besides benefits that help to involve prosumers into Google's capital accumulation system the broader context of consumerism plays into the hands of Silicon Valley firms and their business practices. Contemporary mass media heavily contributes to the consumerist culture by constantly featuring new online services, products, and, ultimately, IT companies. They clearly buy into and stabilize the global informational capitalism and its advertising-based modes of production. According to Bauman (2001) contemporary consumerism is not only characterized by an elevated volume of consumption, but also by the emancipation of consumption from its past instrumentality that used to draw its limits. Consumption now justifies itself only by its own "pleasurability"; consumption is its own purpose, an end in itself. "[C]onsumers should not ever be allowed to 'awake' from their 'dreams'" (Bauman 2001, 13). This quote clearly explains how Marx's (1867) commodity fetishism is anchored in reality. It, however, evokes a concept of capitalist ideology as totally pervading society, as a monolithic concept resembling the one described by Adorno and Marcuse. It takes capitalism at face value and makes critique and efforts towards change difficult.

Turning to Gramsci's notion of hegemony, in contrast, enables us to identify moments of struggle that open up the view for counter-activity and alternative futures. Röhle (2009) described Google's strategy of convincing website providers and users to play by the rules as a clever system of "punishments and rewards". Website providers who follow the rules get rewarded with a good "seat" in Google's search results, while those who transgress the rules by using illicit SEO practices get punished with a lower search engine position (or even an exclusion from the index). Similarly, users who try to opt out of Google's data collecting practices by changing default privacy settings, reconfiguring their web browsers, or turning off cookies are punished with less convenient services than cooperating users get. This shows how Google makes both website providers and users play by the rules. It further shows that Google's hegemony is not fixed or stabilized, but that it is constantly negotiated and made. "As a concept, then, hegemony is inseparable from overtones of struggle" (Eagleton 1991, 115). This struggle has the potential to challenge powerful actors like Google and their algorithmic ideology. If content providers and users broke out of the network dynamic, the power of Google and its whole business model would fall apart. If the media would feature more critical stories about Google's data collecting practices, privacy violations and possible collaborations with secret services dissatisfaction and protest would significantly grow in the public domain; as we have seen in the past months. If politics and law took on a stronger role in the regulation of search technology, limits would be set regarding the collection and use of personal data, but also business practices and advertising schemes. In an age of neoliberal policy, however, governments have widely failed to tame corporate players like Google. Quite on the contrary, the politics of privatization has pushed search on the free market in the first place. This shows that new types of actors, "organic intellectuals" in the words of Gramsci (2012), are needed to challenge corporate players like Google and its ideology.

\section{Post-Democracy, Counter-Struggles and the Organic Intellectual}

The state is increasingly described as "weak" (Bauman 1998) or as an "appendix of the market" (Neckel 2008) in contemporary capitalist structures. In fact, politics itself is changing under the dictate of neoliberalism. Slavoy Žižek (1998) described the current political state as "post-political", while Colin Crouch (2004) framed it as "post-democratic". In a post-democratic society democratic institutions are still formally intact, while political processes are regressing because power is increasingly transferred to economic lobbyists. "Behind this spectacle of the electoral game, politics is really shaped in private by interaction between elected governments and elites that overwhelmingly represent business interests" (Crouch 2004, 4). The negotiation process of the Anti-Counterfeiting Trade 
Agreement (ACTA $)^{2}$ serves as a paradigmatic example of Crouch's (2004) concept of post-democracy. The multinational treaty, supposed to prevent online piracy and copyright infringement, was composed behind closed doors, hidden from the public and crucial institutions including the World Trade Organization (WTO) and the European Parliament. Instead, large intellectual property-based organizations such as the Motion Picture Association of America (MPAA) were active in the negotiations and hence industry-informed interests and the capitalist ideology dominated (a practice that finally resulted in massive protests and the EU's rejection of ACTA in 2012). Another example would be the EU data protection law that is currently negotiated. The binding law will be of central importance not only for European IT companies, but also for US-American players like Google. Consequently, there was heavy lobbying from Silicon Valley companies; more lobbying and industry amendments than ever before in the history of EU legislation. But Edward Snowden and his NSA revelations played a crucial role too. In June 2013 Snowden, a former employee of the CIA and NSA, revealed practices of mass surveillance that American and British intelligence agencies conducted. He further accused tech companies like Google, Facebook, Apple, and others of collaborating with the US National Security Agency (NSA), which created heated media debates. Out of a sudden the issue of large-scale online surveillance and privacy violations hit the headlines all over the world. In fact leftwing media, the Guardian in particular, played a central role in leaking information on NSA scandals and amounts of data commercial players contributed. Snowden's revelations demonstrate entanglements between corporate surveillance and state control. Rather than being victims of the market, governments appear to clearly benefit from commercial players and their data collecting practices in post-9/11 societies. However, counterstruggles are seen on various levels too. The NSA scandal made the European Parliament decide to fend off all amendments from IT companies (for now at least). The accelerated pressure Snowden reached together with critical media clearly created a change in public opinion that could no longer be neglected by policy makers ${ }^{3}$. Whether this will finally result in a data protection law strong enough to set limits for companies like Google remains to be seen in the future.

In Gramsci's terms Snowden may be interpreted as an "organic intellectual". The task of organic intellectuals is to provide subordinate groups with a homogeneous selfconsciousness in the cultural, political and economic fields. Rather than offering "truth" from above, the organic intellectual is supposed to give shape and cohesion to practical understanding deriving from hegemonized groups themselves. "The category of organic intellectual thus spans not only ideologues and philosophers but political activists, industrial technicians, political economists, legal specialists and so on" (Eagleton 1991, 119). Contrary to philosophers withdrawn from social life, figures like Snowden positioned at the center of power have the knowledge to challenge hegemonic actors and their ideological superstructure. They have the expertise and technical know-how to open up opaque networks of information flows, algorithmic logics and collaborations between governmental bodies and commercial players. The Australian journalist Julian Assange was one of the first organic intellectuals of this sort. He created the online platform WikiLeaks publishing secret information concerned with power abuse, corruption and vested interest. Drawing on top-secret information provided by Whistleblowers of various kinds WikiLeaks succeeded in revealing scandals on an unprecedented scale and pushing it right into the public domain with the help of selected mass media ${ }^{4}$. This shows that individuals possessing classified information and technical skills to spread it into society can weaken hegemonic actors, practices and ideologies. Subordinate groups can gain enough power to destabilize hegemonic structures under certain circumstances. It further underlines that political

\footnotetext{
2 http://en.wikipedia.org/wiki/Anti-Counterfeiting_Trade_Agreement (accessed February 6, 2014)

3 http://www.theguardian.com/world/2013/oct/17/eu-rules-data-us-edward-snowden (accessed February 6, 2014).

${ }^{4}$ The most popular leaks include US-Army-related incidences such as the Baghdad airstrike video or standard operations at the Guantánamo Bay detection camp, but also 9/11 messages or Sarah Palin's email communication (Lindgren and Lundström 2011).
} 
activities have migrated from institutional politics to "sub-politics" (Beck 1997). In an age of post-democracy socio-political movements like the ecological movement or feminism played a central role in putting issues like environmental protection and gender equality on the formal political agenda, as Ulrich Beck $(1992,1997)$ argued. The remaining question thus is whether net political issues will find their way into formal politics in the future or whether alternative measures are needed to challenge powerful players like Google and their algorithmic ideology. In the concluding section I will debate this question by pointing out that certain barriers still need to be overcome on the road towards a more sustainable information society.

\section{Conclusions}

In this article I used concepts from ideology critique to show how Google performs, renews and fosters the capitalist ideology. I argued that capitalist modes of production are deeply woven into Google's algorithm and computational mechanisms; that the algorithm is ideological. Moreover, I showed how content providers and users relate to "transnational informational capitalism" (Fuchs 2011a) as a whole in the terms of Althusser. Turning to Gramsci's notion of hegemony I outlined how content providers and users contribute to and stabilize the algorithmic ideology. Rather than conceptualizing them as passive victims of Google, I described them as active participants in Google's capital accumulation cycle with the ability to destabilize its dynamics. How "organic intellectuals" (Gramsci 2012) like Julian Assange or Edward Snowden can help to tame corporate search engines and their ideological superstructure was further discussed. To sustainably challenge hegemonic actors like Google and pave the way towards "value-sensitive innovation" (Allhutter and Hofmann 2010), however, requires more than single individuals. Additional obstacles need to be met, as I finally discuss:

The first obstacle is the vulnerability of organic intellectuals and the inconsistency of their political agendas. Felix Stalder (2010) argued that organic intellectuals, or "superempowered" actors as he coins them, are well suited to trigger large-scale events relatively quickly and cheaply, but that broader social movements would be needed to sustain counter-struggles in the long-term. "Many of the issues that are typical of small groups organised by a charismatic leader seem to affect WikiLeaks as well, such as authoritarianism, lack of internal procedure, dangers of burnout and internal and external attacks on the credibility of that single person (if not worse)" (Stalder 2010). Social movements like "Occupy Wall Street" ${ }^{5}$ challenging global finance or the hacktivist collective "Anonymous" 6 advocating for issues such as freedom of information, independence of the internet, and a new copyright law may be seen as newly emerging phenomena of this sort. On a European level initiatives like the Chaos Computer $\mathrm{Club}^{7}$, which scrutinizes privacy violations

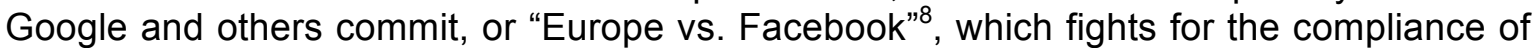
US-based companies with European data protection law, have been created. They may all be seen as locations where counter-struggles form and hegemonic actors are challenged. Rather than following a coherent political agenda, however, they all have very different political goals and visions. While "Occupy Wall Street" is rooted in a radical critique of capitalist society, Anonymous or WikiLeaks stress liberal freedoms without challenging capitalist ideology in and of itself. Gabriella Coleman (2011) argued that Anonymous and WikiLeaks share certain ideological sympathies, such as the freedom of information, but perform very diverse politics: "This diversity of politics results, in part, because geeks and hackers labor on different objects, initiate different types of projects, and are located in many different parts of the world. They are also quite sectarian, engaging in fierce debates as to what constitutes legitimate forms of access, openness, transparency, hacking, privacy, and dissent. As with most political domains, they are bedeviled by ideo-

\footnotetext{
${ }^{5}$ http://occupywallst.org/ (accessed February 6, 2014)

6 http://anonnews.org/ (accessed February 6, 2014)

7 http://www.ccc.de/en/ (accessed February 6, 2014)

8 http://europe-v-facebook.org/EN/en.html (accessed February 6, 2014)
} 
logical or organizational contradictions" (Colemen 2011, 514). The heterogeneity of political visions amongst disparate organic intellectuals and social movements makes it difficult to formulate a net political voice that can make itself heard in formal politics. Contrary to the ecological or feminist movement, which both had a pretty clear political vision, net politics still lacks an overarching goal and vision of alternative digital futures.

The second obstacle is the translation of "sub-political activities" (Beck 1997) into institutional politics. Even if net political initiatives try to enter formal politics and manage to explain that actors like Google cause fundamental socio-political implications that reach far beyond the digital realm, e.g. compromising human rights like data protection, struggles are waiting for them. In Germany, for example, the Enquete Commission "Internet and Digital Society" ${ }^{\prime \prime}$ has been installed by the German parliament. In this commission members of the parliament, but also 17 experts including computer scientists, Internet researchers, media experts, and net activists such as those from the Chaos Computer Club, worked together on net political issues including privacy aspects, security and media literacy. Such forums may help net political issues to enter decision-making processes, but may also dissolve net political ambitions in party politics and processes of economic value creation. The risk is that concessions are made to net activists to keep them in the network of practices stabilizing the power of hegemonic actors, but that the essence, the "nucleus of economic activity" is not touched: "Undoubtedly the fact of hegemony presupposes that account be taken of the interests and the tendencies of the groups over which hegemony is to be exercised, and that a certain compromise equilibrium should be formed - in other words, that the leading group should make sacrifices of an economic-corporate kind. But there is no doubt that such sacrifices and such a compromise cannot touch the essential; for though hegemony is ethico-political, it must also be economic, must necessarily be based on the decisive function exercised by the leading group in the decisive nucleus of economic activity" (Gramsci 2012, 161). This would imply that counter-activities run the risk of getting integrated into hegemonic power relations and, ultimately, end up fostering the dominant algorithmic ideology. Just like the artistic critique helped the "new spirit of capitalism" to endure (Boltanski and Chiapello 2007) ${ }^{10}$, net activists may end up improving corporate internet technologies by provoking privacy-sensitive features that, in turn, raise customer satisfaction further contributing to the brand value of Google and other US companies.

Finally, the third obstacle is that even alternative search technologies enter alliances with corporate players. This means that users, who try to escape for-profit search engines often end up with big players too because the web index, the algorithm and/ or the search results are borrowed from commercial search engines. DuckDuckGo, for example, clearly tries to oppose the dominant algorithmic ideology by providing a search tool that protects privacy rather than sharing personal data with third parties. When looking at its back-end though it becomes obvious, that DuckDuckGo is highly dependent on commercial search engines and their data collecting practices. DuckDuckGo has its own crawler, but only a very small search engine index. Consequently, it displays results from other search engines; non-commercial ones, but also commercial ones including Bing, Yahoo! and Yandex. So even if it does not sell user data itself, it makes use of corporate players and their business models. In addition, it actively contributes to Yahoo's capital accumulation cycle by advertising with Bing ads. Other search engines like Ixquick, MetaGer or Ecosia are similarly dependent on big search engines and their practices (Mager forthcoming). One reason is that building a comprehensive web index has become a very expensive endeavor. Except from peer-to-peer technologies like YaCy, for example, which try to build a

\footnotetext{
${ }^{9}$ http://www.bundestag.de/internetenquete/ (accessed February 6, 2014)

${ }^{10}$ The new capitalist spirit has managed to incorporate what Boltanski and Chiapello (2007) coined, the 'artistic critique' raised by the generation of 1968 and the emerging left. The critique of industrial capitalism as hierarchical, dehumanizing and restricting the individual's freedom, authenticity, autonomy, mobility and creativity. The integration of values like self-management and flexibility in the workplace helped the new spirit of capitalism to endure. The artistic critique may hence be seen as indirectly serving capitalism, which turns critique itself into a fundamental crisis, as Boltanski and Chiapello concluded.
} 
de-central web index running on users' own computers, search engines would need funding to be able to establish an encompassing non-corporate web index. Dirk Lewandowski (forthcoming) suggested providing public funding for creating a public index of the web that would enable programmers to build various search engines on top of it and, as a result, to achieve greater diversity on the search engine market. Contrary to funding one single search engine, funding an open web index would enable the creation of multiple different search tools challenging the dominant algorithmic ideology and offering alternative styles of search. Lewandowski (forthcoming) concluded with arguing that the task of building and maintaining a search engine index may be seen as part of government's role to provide public infrastructure: "The state finances highways used by everyone, ensures that the electrical grid is available to all, and generates and disseminates geo data. Making web data available is no different from these other public services". How such an undertaking may be practically organized, who may contribute money, what institution may be appropriate to run and maintain such an index, what additional barriers may occur on the way towards a public index are all questions that need to be further discussed.

What this article has shown though is that single actors or isolated activities will not be enough to defy big players and their ideological superstructure. Since the capitalist ideology is inscribed in code and manifests in computational logics, since it is stabilized in a complex actor-network and fuelled by neoliberal politics and contemporary consumer culture a collective effort is needed to challenge corporate search technology. Actors from the technological, the political and the socio-cultural realm all have to simultaneously nibble at quasi-monopolistic actors and their ideological Gestalt to revive the search engine market, provide technological choice, protect users, and reconsider advertising and consumer practices. Multiple actors are needed that follow their own ways of irritating Google and working towards alternative styles of search. Programming independent technology, developing public information infrastructures, refining law and regulations, supporting organic intellectuals, changing user practices and routines, questioning marketing strategies and consumer desires are all great first steps towards destabilizing powerful actors like Google. Challenging the dominant algorithmic ideology in the long-term, however, requires more than that. A fundamental debate about where to draw boundaries between the state and the market, how to set limits for corporate players, and how to sustain social justice is needed. A serious discussion about the relation between hegemonic power networks and hegemonized groups is essential. Since technology is not external to society, but rather a central part of it, society needs to change in order to change technology. Alternative socio-political visions need to be developed to conquer capitalist structures and create more democratic information technology, possibly at odds with "frictionless capitalism" (Schröter 2012).

\section{References}

Allhutter, Doris and Roswitha Hofmann. 2010. Deconstructive Design as an Approach for Opening Trading Zones. In: Thinking Machines and the Philosophy of Computer Science: Concepts and Principles, edited by Jordi Vallverdú, 175-192. Hershey: IGI Global.

Althusser, Louis. 1971. Lenin and Philosophy and Other Essays. New York: Monthly Review Press. Accessed February 6, 2014: http://www.marxists.org/reference/archive/althusser/1970/ideology.htm

Barbrook, Richard and Andy Cameron. 1996. The Californian Ideology. Science as Culture 6 (1): 44-72.

Bauman, Zygmunt. 1998. On Glocalization: Or Globalization for Some, Localization for Others. Thesis Eleven 54 (1): 37-49.

Bauman, Zygmunt. 2001. Consuming Life. Journal of Consumer Culture 1(1): 9-29.

Beck, Ulrich. 1992. Risk Society: Towards a New Modernity. New Delhi: Sage.

Beck, Ulrich. 1997. The Reinvention of Politics. Rethinking Modernity in the Global Social Order. Cambridge: Polity Press.

Boltanski, Luc and Ėve Chiapello. 2007. The New Spirit of Capitalism. London: Verso.

Brin, Sergey and Lawrence Page. 1998. The Anatomy of a Large-Scale Hypertextual Web Search Engine. Computer Networks and ISDN Systems 30: 107-17. 
Coleman, Gabriella. 2011. Hacker Politics and Publics. Public Culture 23 (3): 511-516.

Crouch, Colin. 2004. Post-Democracy. Cambridge: Polity.

Eagleton, Terry. 1991. Ideology. An Introduction. London and New York: Verso.

Eklöf, Jenny and Astrid Mager. 2013. Technoscientific Promotion and Biofuel Policy. How the Press and Search Engines Stage the Biofuel Controversy. Media, Culture \& Society 35 (4): 454471.

Elmer, Greg. 2004. Profiling Machines. Cambridge, MA: MIT Press.

Forgacs, David. 1988. A Gramsci Reader. London: Lawrence and Wishart.

Fuchs, Christian. 2011a. Foundations of Critical Media and Information Studies. London and New York: Routledge.

Fuchs, Christian. 2011b. A Contribution to the Critique of the Political Economy of Google. Fast Capitalism 8 (1). Accessed February 6, 2014 : http://www.uta.edu/huma/agger/fastcapitalism/8_1/fuchs8_1.html.

Fuchs, Christian. 2011c. Cognitive Capitalism or Informational Capitalism? The Role of Class in the Information Economy. In Cognitive Capitalism, Education and Digital Labor, edited by Michael Peters and Ergin Bulut, 75-119. New York: Peter Lang.

Gramsci, Antonio. 2012. Selections from the Prison Notebooks. New York: International Publishers.

Hardt, Michael and Antonio Negri. 2000. Empire. Cambridge, MA: Harvard University Press.

Hardt, Michael and Antonio Negri. 2004. Multitude. New York: Penguin.

Herzogenrath-Amelung, Heidi. 2013. Ideology, Critique and Surveillance. TripleC 11 (2): 521-534. Accessed February 6, 2014: http://www.triple-c.at/index.php/tripleC/article/view/499/507

Introna, Lucas and Helen Nissenbaum. 2000. The Public Good Vision of the Internet and the Politics of Search Engines. In Preferred Placement - Knowledge Politics on the Web, edited by Richard Rogers, 25-47. Maastricht: Jan van Eyck Akademy.

Lewandowski, Dirk. Forthcoming. Why We Need an Independent Index of the Web. In Society of the Query Reader, edited by René König and Miriam Rasch. Amsterdam: Institute of Network Cultures.

Lindgren, Simon and Ragnar Lundström. 2011. Pirate Culture and Hacktivist Mobilization: The Cultural and Social Protocols of \#WikiLeaks on Twitter. New Media and Society 13 (6): 9991018.

Mager, Astrid. 2012a. Algorithmic Ideology. How Capitalist Society Shapes Search Engines. Information, Communication \& Society 15 (5): 769-787.

Mager, Astrid. 2012b. Search Engines Matter. From Educating Users Towards Engaging with Online Health Information Practices. Policy \& Internet 4( 2), Article 7.

Mager, Astrid. Forthcoming. Is Small Really Beautiful? Big Search and Its Alternatives. In Society of the Query Reader, edited by René König and Miriam Rasch. Amsterdam: Institute of Network Cultures.

Marx, Karl. 1867. Capital: Volume I. London: Penguin.

Mayer, Katja. 2009. On the Sociometry of Search Engines. A Historical Review of Methods. In Search: The Politics of Search Engines beyond Google, edited by Konrad Becker and Felix Stalder, 54-72. Innsbruck: Studienverlag.

Neckel, Sighard. 2008. Flucht nach vorn. Die Erfolgskultur der Marktgesellschaft, Frankfurt/New York: Campus.

Nettleton, Sarah, Rogers Burrows and Lisa O'Malley. 2005. The Mundane Realities of the Everyday Lay Use of the Internet for Health, and their Consequences for Media Convergence. Sociology of Health \& IIIness 27 (7): 972-992.

Pasquinelli, Matteo. 2009. Google's PageRank Algorithm: A Diagram of Cognitive Capitalism and the Rentier of the Common Intellect. In Search: The Politics of Search Engines beyond Google, edited by Konrad Becker and Felix Stalder, 152-162. Innsbruck: Studienverlag.

Röhle, Theo. 2009. Dissecting the Gatekeepers. Relational Perspectives on the Power of Search Engines. In Search: The Politics of Search Engines beyond Google, edited by Konrad Becker and Felix Stalder, 117-132. Innsbruck: Studienverlag.

Scholz, Trebor. 2013. Digital Labor. The Internet as Playground and Factory. New York and London: Routledge.

Schröter, Jens. 2012. The Internet and "Frictionless Capitalism". TripleC 10 (2): 302-312. Accessed February 6, 2014: http://www.triple-c.at/index.php/tripleC/article/view/425

Seale, Clive. 2005. New Directions for Critical Internet Health Studies: Representing Cancer Experience on the Web. Sociology of Health \& IIIness 27 (4): 515-540. 
Stalder, Felix. 2010. Contain this! Leaks, Whistle-Blowers and the Networked News Ecology. Eurozine. Accessed February 6, 2014: http://www.eurozine.com/articles/2010-11-29-stalderen.html

Stalder, Felix, and Christine Mayer. 2009. The Second Index. Search Engines, Personalization and Surveillance. In Search: The Politics of Search Engines beyond Google, edited by Konrad Becker and Felix Stalder, 98-115. Innsbruck: Studienverlag.

Van Couvering, Elisabeth. 2008. The History of the Internet Search Engine: Navigational Media and the Traffic Commodity. In Web Search. Multidisciplinary Perspectives (Information Science and Knowledge Management), edited by Amanda Spink and Michael Zimmer, 177-206. Berlin/Heidelberg: Springer Verlag.

Vercellone, Carlo. 2007. From Formal Subsumption to General Intellect: Elements from a Marxist Reading of the Thesis of Cognitive Capitalism. Historical Materialism 15 (1): 13-36.

Žižek, Slavoy. 1998. For a Leftist Appropriation of the European Legacy. Journal of Political Ideologies 3 (1): 63-78.

\section{About the Author}

\section{Astrid Mager}

Dr. Phil, is a postdoctoral researcher at the Institute of Technology Assessement (ITA), Austrian Academy of Sciences, and a lecturer at the Department of Science and Technology Studies, University of Vienna. At present, she is leader of the project "Glocal Search. Search technology at the intersection of global capitalism and local socio-political cultures" (funded by the Jubiläumsfonds of the Oesterreichische Nationalbank (OeNB), project number 14702). Her theoretical background is in Science and Technology Studies (STS) and her primary research interests include Internet and society, search engine politics, knowledge production, privacy, digital methods, and critical theory. Recent publications: "Technoscientific promotion and biofuel policy. How the press and search engines stage the biofuel controversy", in Media, Culture \& Society, 2013 (together with Jenny Eklöf), "Algorithmic ideology. How capitalist society shapes search engines", in Information, Communication \& Society, 2012, "Search engines matter: From educating users towards engaging with online health information practices, Policy \& Internet, 2012. Visit http://www.astridmager.net, email: astrid.mager@oeaw.ac.at. 